Afrika Focus, Vol. 11, N 1-4, 1995, pp.157-156

\title{
LE C.D.I.-BWAMANDA ET LE CAFE D'ORIGINE GARANTIE MAX HAVELAAR
}

Le café est un des produits agricoles cultivés dans la région de Bwamanda. A côté de quelques grandes plantations, presque tous les villageois ont quelques caféiers.

$V u$ les options du projet C.D.I.-Bwamanda de mener son action surtout autour des cultures vivrières, le café ne figurait pas dans son programme d'action au départ.

Mais en 1977 quelques agriculteurs (33) exprimaient le désir de commercialiser leur café par le canal du C.D.I. -Bwamanda parce que le prix que les commerçants leur payaient était dérisoire. Les essais furent concluants: le café ainsi transporté pour ces cultivateurs et vendu aux commerçants de café à Kinshasa leur rapportait plus que le double du prix payé par les commerçants locaux.

Après quelques années, les quantités de café ainsi commercialisées via les structures du C.D.I. -Bwamanda devinrent si importantes qu'il fallut chercher des possibilités d'exportation directe de ce produit.

Le C.D.I. -Bwamanda s'était aussi engagé avec la Fondation Max Havelaar aux Pays-Bas en 1988 et y avait été accepté dès le début comme producteur agréé. A cette époque, le prix du café n'avait pas encore chuté, mais la Fondation Max Havelaar vise avant tout la défense des petits producteurs: associés en coopératives ou autres organisations rurales ils peuvent à présent vendre leur café sans passer par les commerçants locaux et négociants internationaux. Les torréfacteurs agréés par Max Havelaar paient un prix minimum juste et garanti; ils procurent un préfinancement de $60 \%$, ce qui permet aux planteurs de rendre la marchandise exportable, et ils s'engagent envers ces associations de producteurs à plus long terme. 
Les premières années de l'existence de l'initiative Max Havelaar, environ $10 \%$ du café disponible a pu être vendu aux torréfacteurs agréés par Max Havelaar.

Pour atteindre plus directement le consommateur belge, le C.D.I.-Bwamanda Belgique asbl, et plus précisément Jos D'Hooghe, ont oeuvré à l'élaboration d'une initiative semblable pour la Belgique. Ainsi a commencé l'asbl Max Havelaar Belgique, dont le C.D.I.-Bwamanda est co-fondateur. Le premier paquet de café belge Max Havelaar fut remis au premier ministre le 15 janvier 1991.

Grâce au prix juste payé à l'agriculteur, le café est devenu une culture de rente fort importante à côté des cultures vivrières. Pour le projet C.D.I.-Bwamanda, le café devient aussi un produit important puisqu'il génère des devises indispensables à l'importation de pièces de rechange et outils nécessaires au bon fonctionnement des infrastructures.

En Belgique, le C.D.I.-Bwamanda aide à promouvoir et à distribuer le café d'origine garantie Max Havelaar. 